\title{
The thermal impact of tourism on a Svalbard glacier cave (Short Communication)
}

\author{
Andreas Alexander \\ Department of Geosciences, The Faculty of Mathematics and Natural Sciences, \\ University of Oslo, 0371 Oslo, Norway
}

\begin{abstract}
Glacier cave visits are an important tourism activity on Svalbard with increasing popularity. This study investigates the thermal effect of touristic visits on the air temperature of a glacier cave on Longyearbreen, a small high-Arctic glacier. Short-term temperature perturbations of up to $1.59^{\circ} \mathrm{C}(42 \%$ local temperature increase) can be linked to human visitors. It is, however, unlikely that the local heat input from touristic visits is high enough to cause a lasting effect on the thermal regime of glacier caves and the surrounding ice.
\end{abstract}

Key words: glacier caves, tourism, cave temperature

DOI: $10.5817 / C P R 2021-1-11$

\section{Introduction}

Svalbard has experienced a tourist boom in the past two decades (Hovelsrud et al. 2020) and it is likely that this trend will continue once the pandemic is over. Particularly adventure based tourism is popular and more and more adventure seeking tourists have been coming during wintertime (e.g. Hovelsrud et al. 2020, Lindberg and Jensen 2020). Among the popular activities are thereby visits of glacier caves. These are caves that are melted into the glacier ice by meltwater during summer and closed in wintertime due to the creep of the surrounding ice (Röthlisberger 1972). In places where the glacier ice is shallow, such cave systems can remain open for dec- ades. During summer they are filled with water, but once the flow of water ceases in winter, some of them can be entered and allow access to the glacier interior. Glacier caves (a cave carved into glacier ice) are thereby not to be mistaken with ice caves, which are caves carved in rock containing ice (Field 2002).

Several glacier caves exist in the vicinity of Longyearbyen and are maintained by local tourist companies to keep them accessible throughout winter. Guided trips are offered either as short stop-overs, designated cave tours, overnight stays or cave ice climbing. Given the popularity of these activities for both tourists and locals, in-

Received May 9, 2021, accepted June 9, 2021.

*Corresponding author: A. Alexander <andreas.alexander@geo.uio.no>

Acknowledgements: This research has been supported by the Research Council of Norway (Arctic Field Grant, grant no. 2019/296184) and the Svalbard Environmental Protection Fund (project 17/31). The data loggers used during this study were kindly provided by H.H. Christiansen. Erik Schytt Holmlund and Jaros Obu helped during the fieldwork. Hurtigruten Svalbard AS provided information about cave visits. I want to further thank M. Bartak for inviting me to contribute to this issue of CPR. 
frequent accidents occur. Particularly one incident stands out, when a group of visitors was trapped inside a cave at Longyearbreen and had to dig their way out after part of a passage had collapsed behind the group ([1]-Svalbardposten 2012). In the light of this background, this paper sets out to investigate the effect that tourism has on glacier caves. In particular, the thermal effect is investigated as the question has

\section{Methods}

\section{Study site}

Longyearbreen is a small valley glacier at $78.18^{\circ} \mathrm{N}$ and $15.5^{\circ} \mathrm{E}$, located $1.7 \mathrm{~km}$ south of Longyearbyen, the main settlement of Svalbard (Fig. 1). The $3.7 \mathrm{~km}$ long glacier extends from 250 to $800 \mathrm{~m}$ above sea level on a north-facing slope. Glaciological and hydrological characteristics of the glacier were reported by Etzelmüller et al. (2000).

A deeply incised lateral supraglacial channel can be found on the glaciers western side and has frequently been studied over the recent years (e.g. Hansen et al. 2020). Snow closes off the channel in wintertime, forming a cave system. Access to

\section{Visitor statistics}

Cave visitor statistics were provided by Hurtigruten Svalbard AS. The data were thereby given in three-hour intervals, including cave visit, pick-up from and delivery to town, as well as the drive up and down the glacier. The actual retention time in the cave is therefore unknown. Several

\section{Cave mapping}

The cave system was mapped using a laser distance meter modified for speleological purposes, also called DistoX (Heeb 2014). The device measures distance, com- arisen, if the heat induced by human visitors is sufficient to create thermal variations large enough to induce ice strain as a result of frequent freezing and thawing. This study therefore presents measurements of cave air temperatures from Longyearbreen, alongside visitor statistics, and discusses the local heat perturbations caused by cave visitors.

this cave is maintained by local tourism companies via the construction of an igloo on the surface. As the cave entrance is located only $4.3 \mathrm{~km}$ south of Longyearbyen, the cave is visited several times daily throughout winter (summer visits are not possible due to meltwater filling the cave). Visits can thereby be both: Organized touristic ventures, as well as short-stopovers by local inhabitants passing by along the snowmobile track. In 2019 the accessible part of the cave was rather short with $84 \mathrm{~m}$ cave length, extending to a depth of $13 \mathrm{~m}$ below the glacier surface.

other companies further offer guided tours to the same cave system, in addition to many privately organized visits. No information on these visits is available and they are therefore not included in the visitor statistics used for this study.

pass bearing and inclination along a line transect survey and transfers the readings to a PDA device with installed PocketTopo software (Heeb 2014). 


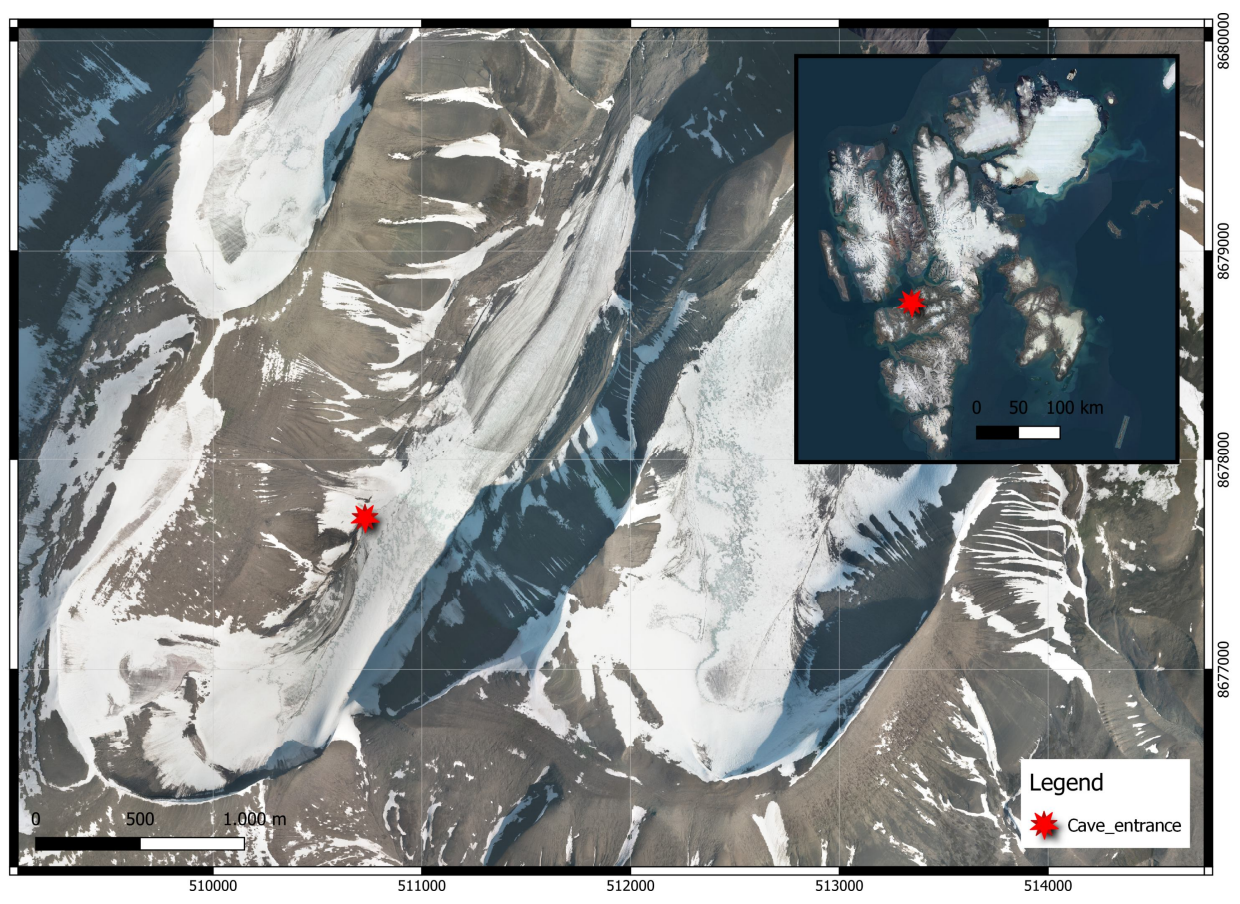

Fig. 1. Overview map showing the location of Longyearbreen on the Svalbard archipelago and the cave entrance. Coordinate system: WGS84 UTM 33 North. Background image: Norwegian Polar Institute.

The device was calibrated before the measurements, following the standard calibration procedures outlined in the DistoX calibration manual (Heeb 2013). Handheld GPS coordinates (accuracy $3 \mathrm{~m}$ ) served as a starting point. The compass bearings were corrected for the local magnetic declination and the measurements were transformed into UTM coordinates and plotted using the PocketTopo software.

\section{Logger installations, meteorological data and processing}

Three TinyTag Plus 2 data loggers with internally mounted $10 \mathrm{~K}$ NTC Thermistor sensor $\left(0.01^{\circ} \mathrm{C}\right.$ resolution and $0.35^{\circ} \mathrm{C}$ accuracy at $0^{\circ} \mathrm{C}$ temperature) were mounted $2 \mathrm{~m}$ above the cave floor and set to a 5 min. logging interval (named 'Entrance', 'Middle' and 'End' according to their location within the cave system, see Fig. 2). The loggers were installed on 04. February 2019 and removed on 12. March 2019.

Hourly air temperature data from the Svalbard Airport weather station were downloaded from the Norwegian meteoro- logical service [2].

All temperature data were processed using MATLAB R2020b. For each logger (Entrance, Middle, End) the temperature increase during known visits was calculated as the maximum temperature during the three-hour interval and the temperature at the start of the interval. The residual temperature was computed as the temperature difference between the temperature at the end and the start of each three-hour interval. Mean, min and max values were further calculated for all 43 known visits. 
A

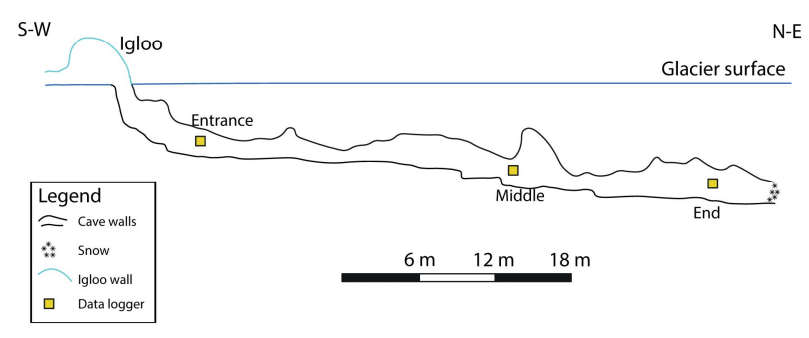

B

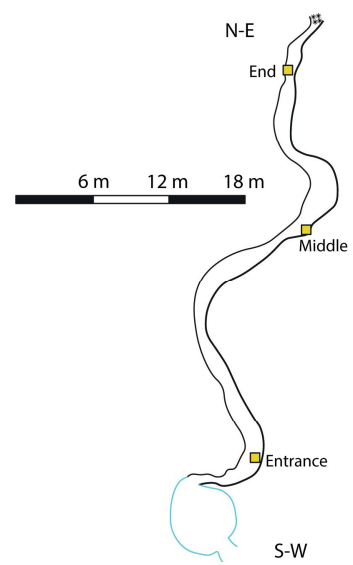

Fig. 2. Cave map of the investigated cave system at Longyearbreen showing logger locations. A) Profile. B) Plane view.

\section{Results}

During the study period, the average surface air temperature at Svalbard Airport was $-14.07^{\circ} \mathrm{C}$, with a short warm period in late-February (Fig. 3A). The average cave air temperature at the Entrance logger was $-7.68^{\circ} \mathrm{C}$ throughout the entire period. The overall temperature trend is following the one from the surface air temperature (Fig. 3B). The average air temperatures at the Middle and the End logger are $-3.68^{\circ} \mathrm{C}$ and $-3.62^{\circ} \mathrm{C}$ respectively. Both loggers record no long-term temperature fluctuations (Fig. 3C).
All three logger records show shortterm temperature perturbations (up to $5 \mathrm{~h}$ ) during and outside times of known cave visits. In total 517 known visits occurred during the study period (Fig. 3D). The highest temperature increase can thereby be found at the End logger with $1.59^{\circ} \mathrm{C}$ ( $42 \%$ increase). Most increases are, however, short-lived and the residuals (Table 1 and Fig. 4) are thus low. In some occasions a cooling of the cave system has been observed during known visits.

\begin{tabular}{lllllll}
\hline & \multicolumn{3}{c}{ Increase } & & Residual \\
\cline { 2 - 7 } & Mean & Max & Min & Mean & Max & Min \\
\hline Entrance & 0.46 & 1.42 & 0 & 0.06 & 1.07 & -0.63 \\
Middle & 0.18 & 0.45 & 0 & 0.01 & 0.19 & -0.37 \\
End & 0.39 & 1.59 & 0.01 & 0.04 & 0.19 & -0.15 \\
\hline
\end{tabular}

Table 1. Average, maximum and minimum temperature increase and residual at measurement locations connected to cave visits. All measurements are given in ${ }^{\circ} \mathrm{C}$. 

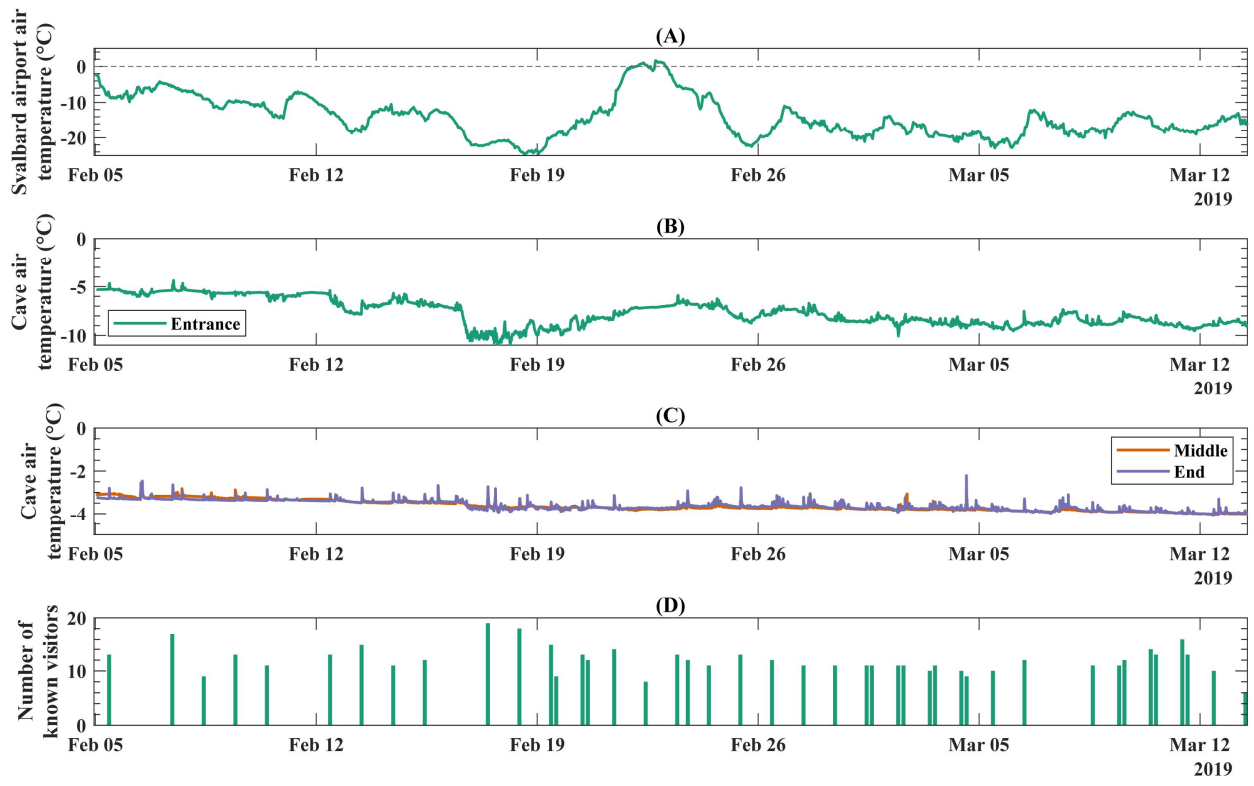

Fig. 3. Recorded data between 04. Feb. 2019 and 12. Mar. 2019. A) Hourly air temperature at Svalbard airport. B) 5 min. interval cave air temperature at the Entrance logger. C) 5 min. interval cave air temperatures at the Middle and End loggers. D) Number of known visitors during the observation period.
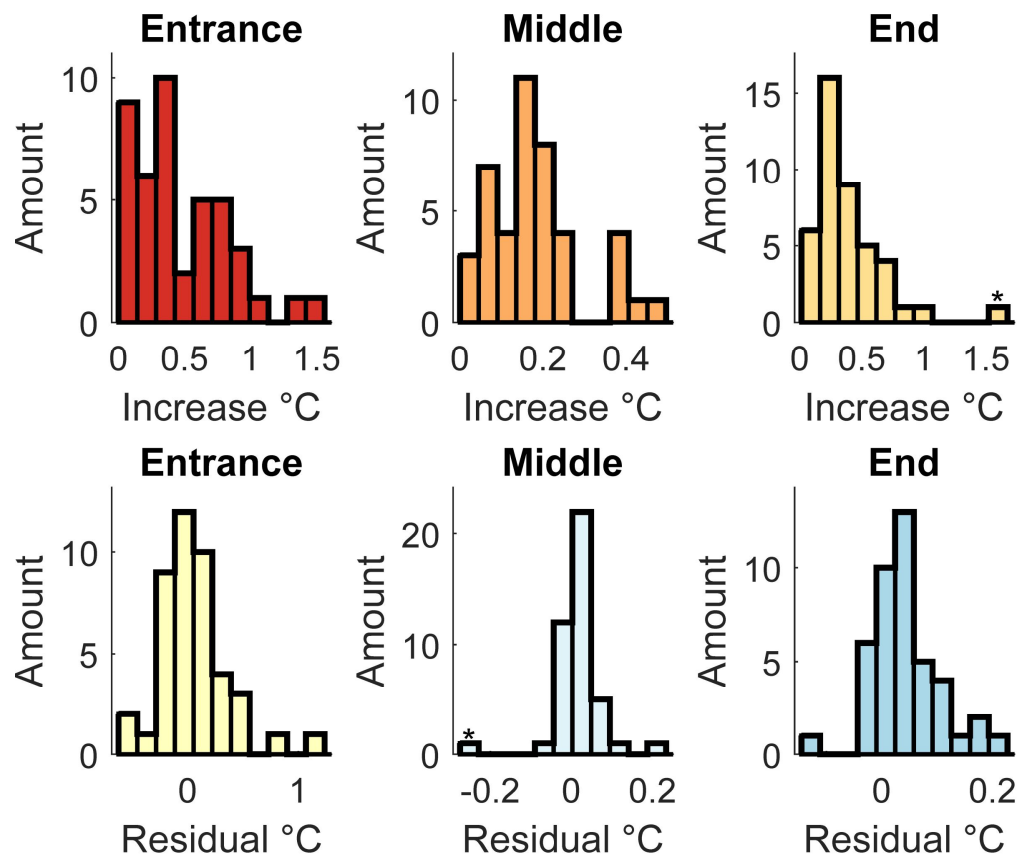

Fig. 4. Histograms showing the distribution of temperature increase and residual for each logger. 


\section{Discussion}

In comparison to the temperature records from glacier cave systems not used for touristic purposes (Alexander et al. 2020), clear and frequent temperature perturbations are present. These can be linked to the heat input from cave visitors in all cases where information about visits is available. As the available data represent only a fraction of the actual cave visits, it can be assumed that all temperature spikes, recorded inside the cave, are connected to human visitors.

Particularly the entrance of the cave is exposed to high temperature variations. As it is closer to the surface, its thermal regime is still partly controlled by heat exchange with the atmosphere. Visitors tend to gather at the entrance before venturing deeper into the cave, thus increasing the local heat input close to the Entrance logger.

This part of the cave is further directly connected to the atmosphere during cave visits, as a wooden plate, covering the entrance, is removed to enter the cave. As a result, cold air drains into the cave system during visits while warm air can vent out, thereby outweighing the heat input from the visitors.

The end of the cave system is the deepest part and thus experiences the best insulation from the surface air temperature. This makes the thermal regime of this cave part more sensitive to local heat input. Visitors further tend to gather at the cave end before turning around, explaining the high

\section{Conclusion}

This study has investigated the thermal effect of touristic visits on glacier caves. It is shown that such visits cause local temperature perturbations of up to $42 \%$ of the cave air temperature. These effects are, however, short-lived and mostly diminish within one hour. Touristic visits further establish a direct connection to the atmos- temperature perturbations recorded by the End logger.

A direct link between the amount of visitors and the magnitude of the caused temperature perturbation can, however, not be established (Pearson correlation coefficients of $0.21,0.46$ and 0.29 for Entrance, Middle and End respectively). The temperature perturbations are further short-lived and mostly diminish within one hour.

The data show that touristic visits are unlikely to have a thermal effect large enough to affect ice temperatures and thus stability. However, this study is limited to only one month during the coldest period of the year and a single cave system close to the glacier surface. Conclusive statements would therefore require further investigations from deeper and thus warmer caves, as well as over extended periods of time, where effects from cold-air draining into the cave are not prevailing. Further, the exact resident times and movement patterns of cave visitors would be required and airflow patterns within the cave to be established (e.g. via the calcFLOW model by Meyer et al. 2016). This could then be used to run numerical models to fully understand the thermal impact of visitors on glacier caves. Another aspect requiring further investigation would be the question if tourism can introduce foreign organisms into glacier caves that could subsequently enter sub- and proglacial ecosystems via meltwater transport in summer.

phere, allowing cold air to drain into the cave, outweighing local heat input during cold periods. It is therefore unlikely that human visitors can introduce enough heat to have an effect on ice stability. The data of this study are, however, limited and the results therefore not conclusive, requiring further investigations. 


\section{References}

Alexander, A., Obu, J., Schuler, T. V., KäÄB, A. and Christiansen, H. H. (2020): Subglacial permafrost dynamics and erosion inside subglacial channels driven by surface events in Svalbard. The Cryosphere, 14: 4217-4231. doi: 10.5194/tc-14-4217-2020.

EtZelmüller, B., ØDegård, R. S., Vatne, G., Mysterud, R. S., Tonning, T. and Sollid, J. L. (2000): Glacier characteristics and sediment transfer system of Longyearbreen and Larsbreen, western Spitsbergen. Norsk Geografisk Tidsskrift - Norwegian Journal of Geography, 54(4): 157-168. doi: 10.1080/002919500448530.

FIELD, M. S. (2002): A lexicon of cave and karst terminology with special reference to environmental karst hydrology. U.S. Environmental Protection Agency. Office of Research and Development, National Center for Environmental Assessment, Washington Office, Washington, DC, EPA/600/R-99/006, 221 p.

Hansen, L. U., Piotrowski, J. A, Benn, D. I. and Sevestre, H. (2020): A cross-validated threedimensional model of an englacial and subglacial drainage system in a High-Arctic glacier. Journal of Glaciology, 256: 278-290. doi: 10.1017/jog.2020.1.

HeEB, B. (2013): DistoX2 calibration manual. Available at: https://paperless.bheeb.ch/download/ DistoX2_CalibrationManual.pdf (last access: 4 December 2019).

HeEB, B. (2014): The next generation of the DistoX cave surveying instrument. CREG Journal, 88: 5-8.

Hovelsrud, G. K., Kaltenborn, B. P. and Olsen, J. (2020): Svalbard in transition: Adaptation to cross-scale changes in Longyearbyen. The Polar Journal, 10(2): 420-442. doi: 10.1080/ 2154896X.2020.1819016,

LindBerG, F., JENSEN, Ø. (2020): Adventure regime of tourism experiences. Current Issues in Tourism. doi: 10.1080/13683500.2020.1854196.

Meyer, C., Meyer, U., Pflitsch, A. and Maggi, V. (2016): Analyzing airflow in static ice caves by using the calcFLOW method. The Cryosphere, 10: 879-894. doi: 10.5194/tc-10-879-2016.

RÖTHLISBERGER, H. (1972): Water pressure in intra- and subglacial channels. Journal of Glaciology, 11(62): 177-203. doi: 10.3189/S0022143000022188.

\section{Web sources / Other sources}

[1] Svalbardposten (2012): Ras i isgrotta. https://svalbardposten.no/nyheter/ras-i-isgrotta/19.244. Last accessed: 09.05.2021

[2] Norwegian Centre for Climate Services (2021) https://seklima.met.no 